for electron and positron scattering are still housed in temporary quarters. It is hoped that eventually all the rest of the research work of the Department as well as the workshop and lecture theatres will be accommodated in an adjacent building under conditions as satisfactory as those of the new wing.

\section{THE PHARMACEUTICAL SOCIETY}

$\mathrm{O}$

$\mathrm{N}$ May 23, the Pharmaceutical Society of Great Britain held a reception to mark the granting of its new constitution. Founded in 1841, the Society received a Royal Charter in 1843. Modifications were afterwards made in its constitution by the various Pharmacy Acts. A Supplemental Charter granted in 1953, virtually replacing the original, and the Pharmacy Act 1953 have now brought the Society's constitution into line with present-day circumstances and needs. A reception was held at 66 Portland Place, W.1, through the kindness of the Royal Institute of British Architects, to mark the occasion, and H.R.H. the Duke of Edinburgh attended the reception and was presented during the evening with his diploma as the first Honorary Fellow of the Society.

The Society's charters and grant of arms were on view, together with rare books from the Society's Library. Incunabula were represented by the "Latin Herbarius" printed at Passau in 1485, and the 1491 edition of the " $(\mathrm{H})$ ortus Sanitatis" from the press of Jacob Meydenbach at Mainz. The latter, a treatise on herbs, animals, birds, fishes, stones and minerals, showed the illustration of the Bausor tree, believed to exhale a narcotic poison. In the illustration two men lie beneath its branches, apparently in the sleep of death. Manuscripts included an early recipe book in Elizabethan hand and a fine English medical work of the seventeenth century, bound in contemporary calf. A copy of the second issue of the first "London Pharmacopoia" of 1618 published in December of that year attracted much interest. 'The first issue was published in May, but it was so full of errors that all copies were officially destroyed; a facsimile of it was exhibited. The first quarto edition, published in 1699, of the well-known satirical poem "The Dispensary", by Dr. Samuel Garth, dealing with the quarrels between the Society of Apothecaries and the Royal College of Physicians, was also on view.

At the request of the Duke of Edinburgh, an exhibition had been staged to portray the pharmaceutical industry's contribution to medical and veterinary science.

Featured on twenty large panels, arranged by the Association of the British Pharmaceutical Industry, was a representative selection of the drugs discovered and developed in recent years, which have revolutionized the practice of medicine and have made a significant contribution to advances in surgery.

In an introductory panel, some statistics of the industry were shown graphically. Its production, valued at $£ 19$ million in 1935 , had risen to $£ 120$ million in 1954. The numbers of persons employed by the industry in research, development, manu. facture both primary and secondary, and in distribution to the pharmacist, doctor and hospital, had risen much less than proportionately-from 22,000 in 1935 to 53,000 in 1951. Its exports, valued at $£ 3.28$ million in 1938 , amounted in value to $£ 33.6$ million in 1954.
The tendency to think of modern medicine in terms of sulphonamides, antibiotics and other recently discovered life-saving drugs often leads to the supposition that symptomatic treatment no longer has a place in medicine. As a reminder that preparations of vegetable drugs and their active principles are still used in considerable though steadily diminishing amounts, a panel was included featuring a flow chart of the manufacture of a galenical, photographs of fields of henbane, foxglove (digitalis) and deadly nightshade (belladonna), together with specimens of an opium poppy capsule, gentian root, nux vomica seeds, ergot sclerotia, and preparations of digitalis. Roots of Rauwolfia serpentaria and its principal alkaloid reserpine, now much used for mild hypertension and psychotic disorders, were also shown. The commercial development of the synthesis of atropine and the tropane alkaloids was illustrated by a photograph of the British plant now used for this purpose.

The developments in anæsthesia since Sir James Young Simpson introduced the use of chloroform in Edinburgh in 1847 were exemplified by the newer anæsthetics such as cyclopropane, trichloroethylene (including its application by self-administration) and thiopentone (used intravenously).

Muscle relaxants, which have a temporarily paralysing action and greatly facilitate modern surgery by avoiding the need for almost toxic doses of anæsthetic, derive their application from the isolation of the alkaloid tubocurarine from the South American arrow poison, curare. Poison-tipped darts and blowpipe, crystalline curare and a curare gourd prefaced specimens of tubocurarine and the more recently developed synthetic analogues, gallamine triethiodide and laudexium methylsulphate.

The development of specialized contrast media by the British pharmaceutical industry has enabled the medical use of X-rays to be extended, and in addition to the detection of bone fractures they now aid the radiologist to give a prominent picture of the gallbladder, arteries, bronchial tree, the urinary tract and other systems and organs. Among the radiological agents displayed were barium sulphate for preparation of barium meals, diodone, iodized oil, propyliodone, iodoxyl and ethyl iodophenylundecylate.

The use of injectable fluids to restore blood volume in cases of patients suffering from shock and loss of blood, as an alternative to the transfusion of blood, began with the discovery of the value of gum acaciasaline injection during the First World War. Dextran and polyvinylpyrrolidone were exhibited as newer agents which avoid the adverse effects of acaciasaline on the blood and liver. They are polymers of sufficiently high molecular weight not to be excreted too quickly.

The antibiotics formed the subject of two panels and exhibits. A photograph of the late Sir Alexander Fleming fittingly introduced the panels, which included a flow chart of penicillin manufacture, a chart depicting the rate of growth of manufacture and export of penicillin and its preparations, and another showing the estimation of sensitivity of organisms to antibiotics. Specimens shown of the different forms of presentation of penicillin included vials of penicillin $\vec{G}$ for preparation of the injection, of procaine penicillin, of oral suspension, tablets and ointment, and of penethamate hydriodide and benethamine penicillin. Specimens were also shown of streptomycin sulphate, chloramphenicol capsules, aureomycin, oxytetracycline, tyrothricin lozenges, polymixin-bacitracin ointment, neomycin, viomycin, 
and erythromycin. The application of antibiotics as supplements in animal feeding to increase the rate of growth of animals was illustrated by photographs of piglets at different ages after so feeding.

Antihistamines exhibited included diphenhydramine, mepyramine, promethazine, antazoline, chlorcyclizine and phenindamine, together with a diagram of the action of antihistamines and a reminder of their value in preventing travel sickness and nausea and vomiting due to other causes. It was only in 1910 that Sir Henry Dale, then working in the research laboratories of a British pharmaceutical company, had fully investigated histamine, a natural constituent of the living tissues, and the liberation of which is largely responsible for allergic manifestations. It was only subsequent to 1910 that the search for histamine antagonists began. For some years the main histamine antagonist was adrenaline. More recently a homologue, isoprenaline, has been much used as its sulphate. What are now called 'antihistarnines' have the more specific action of neutralizing directly the physiological effects of histamine.

Anticoagulants which have revolutionized the treatment of thrombo-embolic disease interfere with the process of coagulation of the blood, a process illustrated by a chart. 'The exhibits included the naturally occurring heparin, extracted from lung or liver tissue, the synthetic anticoagulants, dicoumarol and its derivatives, phenylindanedione, as well as dextran sulphate discovered by Ricketts and Walton at Birmingham.

The importance of antimalarials was illustrated by a map showing the world incidence of malaria, and a chart illustrating the life-cycle of the malaria parasite and photographs showing methods of eradication of mosquitoes. Antimalarials exhibited included quinine both as tablets and injection, amodiaquine, pyrimethamine, chloroquine, primaquine and proguanil.

Some of the problems of tropical medicine were illustrated by photographs of patients suffering from elephantiasis, leprosy, bilharzia and trypanosomiasis, and by a table showing the carriers of and parasites responsible for these diseases and the modern methods used for their treatment. A tank of snails served as a reminder of the problems of eradication of bilharzia from endemic areas. Specimens of medicaments shown included the anti-leprotic sulphones, tryparsamide, lucanthone, sodium stibogluconate, diethylcarbamazine, suramin, pentamidine isethionate and yellow-fever vaccine.

A panel devoted to veterinary medicine emphasized the application of the newer human remedies to the treatment of animal diseases, as well as the develop. ment of specific serological products. Limitations of space scarcely permitted justice to be done to the contributions of the industry to the advances in animal medicine.

A portrait of Lord Lister introduced recent developments in antiseptics, which were exemplified by specimens of acridine derivatives, halogenated phenols such as chloroxylenol, $p$-chloro- $m$-xylenol and -cresol, and the quaternary ammonium compounds cetrimide, benzalkonium and domiphen bromide.

The progress in the British development of insulin manufacture since Banting and Best's discovery of insulin in 1922 was dramatically illustrated by a chart of the price reductions that have followed its increasingly large-scale production to meet the demands of diabetics throughout the world. Charts showed the duration of reduction of blood sugar by soluble insulin and its complexes with globin and protamine in the presence of zinc and of the more recently developed insulin zine suspensions.

Other hormones and their derivatives exhibited included testosterone, methyl testosterono, cestrone, ethinylœstradiol, stilbœstrol and cortisone acetate (manufactured in Britain from hecogenin isolated from sisal). Supporting charts showed the chemical inter-relationships of the medicinally used steroids and the influence of hormones in the menstrual cycle.

Immunological products were introduced by a portrait of Jenner, a chart showing the changed incidence of diphtheria in recent years and photographs of sera manufacture, the preparation of B.C.G. vaccine and inoculation of culture media. In addition to specimens of different sera and vaccines, there were shown publicly for the first time specimens of the Salk antipoliomyelitis vaccine manufactured by a British firm.

Specimens of an almost complete range of the vitamins used medicinally, including about a gram of crystalline cyanocobalamin (vitamin $B_{12}$ ), supported illustrations of vitamin-deficiency states and of plant employed in the manufacture of certain vitamins by synthetic methods.

Following Domagk's discovery of the value of prontosil in chemotherapy, and of Fourneau's recognition that the sulphanilamide fragment was wholly responsible for its action, the synthesis and evaluation of sulphapyridine by a British firm set the pattern for the highly effective sulphonamides now used in chemotherapy. Despite the introduction of antibiotics, the sulphonamides are still widely used in the treatment of many diseases and have aided in the avoidance of, and in dealing with, drug-resistant strains of organisms. A photograph of Dr. A. J. Ewins introduced a panel depicting various aspects of sulphonamide evaluation and therapy, and specimens of sulphonamides displayed included sulphadiazine, sulphadimidine, sulphafurazole, sulpha. merazine, sulphathiazole, phthalyl- and succinylsulphathiazoles, sulphaguanidine, sulphasomidine and sulphacetamide both in powder form and in tablets.

The assistance given by analgesics and hypnotics in coping with the exigencies of modern civilization have led to the search for, discovery and manufacture of, the wide range of barbiturates, specimens of short-, medium- and long-acting ones being shown. Although substantial quantities of morphine are still manufactured and used, synthetic analogues such as pethidine, of which a specimen was shown, are steadily replacing morphine in many of its applications.

The skills of the organic chemist, the pharmacologist, the biochemist, the bacteriologist, the microbiologist and the chemical engineer are of little avail to modern medicine unless the products emerging from their work are presented in stable, effective and acceptable form for use by the patient or medical practitioner. It is to the formulation, preparation and directions for use of the whole range of medicaments that the pharmacist applies his training and knowledge. It was therefore fitting that the final exhibit should be devoted to specimens of the forms in which medicaments are used: tablets, pills, capsules, ampoules and multiple-dose injection containers, suppositories, bougies, pessaries, cachets, lozenges, pastilles, creams, ointments, dusting pow'ders, mixtures, syrups, mouth washes, paints, liniments, lotions and eye drops. 